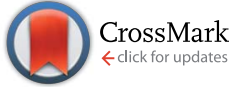

Cite this: RSC Adv., 2016, 6, 5865

\title{
Capacitive deionization in organic solutions: case study using propylene carbonate $\uparrow$
}

\begin{abstract}
S. Porada, ${ }^{a}$ G. Feng, ${ }^{\text {b } M . ~ E . ~ S u s s ~}{ }^{c}$ and V. Presser ${ }^{\star a d}$
Capacitive deionization (CDI) is an emerging technology for the energy-efficient removal of dissolved ions from aqueous solutions. Expanding this technology to non-aqueous media, we present an experimental characterization of a pair of porous carbon electrodes towards electrosorption of dissolved ions in propylene carbonate. We demonstrate that application of CDI technology for treatment of an organic solution with an electrochemical stability window beyond $1.2 \mathrm{~V}$ allows for a higher salt removal capacity and higher charge efficiency as compared to CDI applied for treatment of aqueous electrolytes. Further, we show that using conductivity measurements of the stream emerging from the CDI cell combined with an equilibrium electric double-layer structure model, we can gain insights into charge compensation mechanisms and ion distribution in carbon nanopores.
\end{abstract}

Received 7th October 2015
Accepted 5th January 2016

DOI: $10.1039 / \mathrm{c} 5 \mathrm{ra20786j}$

www.rsc.org/advances energy efficient separation when using relatively dilute electrolyte solutions (i.e., where the molecules of water outnumber by roughly three or more orders of magnitude the number of ions). ${ }^{7}$ Despite CDI's many benefits, a fundamental limitation to the usable cell voltage range is the narrow electrochemical stability window of water. ${ }^{4}$ As a consequence, the maximum voltage in typical CDI systems does not exceed 1.2 to $1.4 \mathrm{~V}^{4,8}$ At electric potentials above this level, water decomposition occurs at the electrodes via water electrolysis, which acts as a parasitic energy loss and a source of unwanted gas generation. Thus, the maximum $\mathrm{NaCl}$ adsorption capacity for CDI systems based on capacitive electrodes remains limited to roughly $20 \mathrm{mg}_{\mathrm{NaCl}}$ $\mathrm{g}_{\text {carbon }}{ }^{-1}$, when normalized by the mass of the highly porous carbon electrodes (typically with around $1500-2000 \mathrm{~m}^{2} \mathrm{~g}^{-1}$ specific surface area). ${ }^{9-12}$

While CDI has been proven to be a versatile and powerful tool for separation processes in aqueous solutions, little attention has been paid to separations achievable by CDI in electrolyte systems using organic solvents. This is despite the enormous amount of electrolyte-based separations performed in organic solvents throughout the chemical and pharmaceutical industries. ${ }^{13}$ In this study, using a proof-of-concept system, we demonstrate for the first time that CDI can be a useful tool for the large field of separations in organic solvents. Within the family of electrosorption technologies, CDI in organic solvents combines the use of organic solvents typical to supercapacitors with operation at low ion concentration typical to CDI, thus establishing a new operational regime for these technologies (see Fig. 1A).

To compare electrosorption properties of carbon electrodes for ion removal from aqueous and organic electrolytes, two identical cells were constructed where the electrolyte flows inbetween a pair of electrodes (flow-between geometry). One cell 66123 Saarbrücken, Germany

$\dagger$ Electronic supplementary information (ESI) available. See DOI: 10.1039/c5ra20786j 


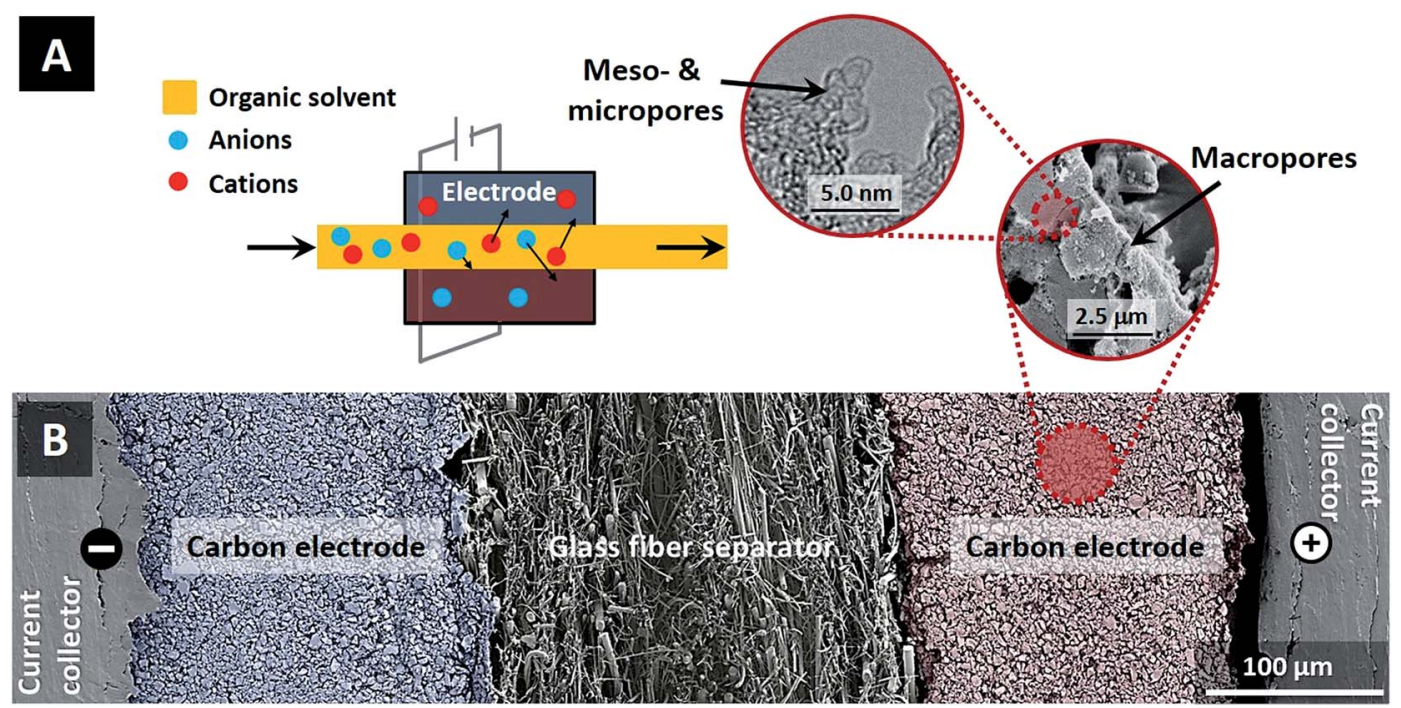

Fig. 1 (A) Flow between setup in which stream of an organic solvent flows in-between two electrodes composed of porous carbon particles. As a cell voltage is applied to these electrodes, ions migrate and are removed from the solvent stream and reversibly electrosorbed at the fluid/solidinterface as the electrical double-layer forms. (B) SEM picture of one flow cell consisting of two graphite current collectors, two porous carbon electrodes and a spacer flow channel. Zoom in pictures show three levels of porosity (macro-, meso-, and micropores) present within the electrodes. The negatively and positively polarized electrodes are presented in false color to match the color of the schematic in panel (A).

was for CDI electrosorption with the aqueous electrolyte of $\mathrm{NaCl}$, and the second for the organic electrolyte system, where we use tetraethylammonium tetrafluoroborate salt dissolved in propylene carbonate (TEA-BF $4 / \mathrm{PC}$ ), see Fig. $1 \mathrm{~A}$. Materials used in this study were graphite current collectors (Sigraflex Z, SGL Carbon, Germany), carbon composite electrodes with a thickness of $\sim 250 \mu \mathrm{m}$ consisting of $90 \mathrm{wt} \%$ of activated carbon (YP50-F, Kuraray Chemical, Japan; see ESI Fig. S1 $†$ ) and $10 \mathrm{wt} \%$ of polyvinylidene fluoride (Kynar HSV 900, Arkema Inc., USA), and a glass fiber spacer (Millipore, Ireland, thickness $\sim 250 \mu \mathrm{m})$. Fig. 1B shows a scanning electron micrograph (SEM) of the cross-section of the CDI cell, as well as an SEM image of the electrode macropore structure, and a transmission electron microscope (TEM) micrograph of the mesoand micropore structure. Carbon electrodes were fabricated using similar procedure as outlined in ref. 14 . In this study we used a flow-between cell containing four pairs of carbon electrodes with total activated carbon mass equal to $\sim 3.6$ g. A constant flow rate of $\Phi=7.5 \mathrm{~mL} \mathrm{~min}{ }^{-1}$ per flow channel is used throughout this work (total flow of $\Phi=30 \mathrm{~mL} \mathrm{~min}^{-1}$ ). Electrochemical measurements were carried out with a potentiostat (VSP30 from Bio-Logic, France) using chronoamperometry (CAM) at several different levels of applied cell voltage, while salt concentration is measured on-line via conductivity sensor (856 conductivity module coupled with 5 ring conductivity measuring cells, Metrohm AG, Switzerland). The measured conductivity was converted to salt concentration using a calibration function (see ESI Fig. S2 $\dagger$ ). The salt adsorption capacity and the measured charge are defined as per mass of active material in both electrodes. Electric charge was calculated from the discharge current after correcting for the leakage current measured at the end of each desorption step.
The $\mathrm{NaCl} / \mathrm{H}_{2} \mathrm{O}$ system was operated in a single-pass mode, which is where the feed passes through the cell a single time and is then mixed into a large reservoir $(10.5 \mathrm{~L})$, with negligible change in the reservoir ionic strength. The TEA-BF $/ \mathrm{PC}$ system was operated in a batch-mode, where the electrolyte in the small-volume reservoir of $\sim 98 \mathrm{~mL}$ and $566 \mathrm{~mL}$ for $5 \mathrm{mM}$ and 50 $\mathrm{mM}$ feeds, respectively, was recirculated through the cell until a steady effluent conductivity was reached (so reservoir ionic strength was significantly changed). For more details on batch versus single-pass experimental modes see ref. 4 , or the schematics provided in Fig. 2A (for single pass mode) and Fig. 2B (for batch mode). CDI experiments with organic electrolyte were performed in batch mode operation due to the slow ion electrosorption kinetics of this system. In order to probe the physical source of the slow kinetics observed, we performed molecular dynamics simulations which show that the diffusivity of TEA-BF ${ }_{4}$ in PC is about one order of magnitude lower than for $\mathrm{NaCl}$ in water when both systems are at a concentration of 50 $\mathrm{mM}$ (see ESI Fig. S3 and Tables S1 and S2 $\dagger$ ). This large difference in predicted diffusivity is likely the cause of the slow ion electrosorption rate observed when TEA-BF ${ }_{4}$ in PC was studied.

In Fig. 2A, we provide experimental effluent conductivity data taken form $\mathrm{NaCl} / \mathrm{H}_{2} \mathrm{O}$ system during single-pass chargedischarge cycling, and in Fig. 2B the data taken from the TEA$\mathrm{BF}_{4} / \mathrm{PC}$ system during batch-mode cycling. For the CDI experiments with aqueous electrolyte, we used experimental conditions typical to ion removal from aqueous electrolyte studies, with $1.2 \mathrm{~V}$ applied during charging, $0 \mathrm{~V}$ applied during discharging, and a feed with $50 \mathrm{mM} \mathrm{NaCl}$ solution. Two full charge-discharge cycles are shown, characterized by the sharp dip in conductivity upon initiating cell charging, and sharp rise in conductivity upon shorting the electrodes. For the CDI experiments with an organic solvent, applied voltages varied 

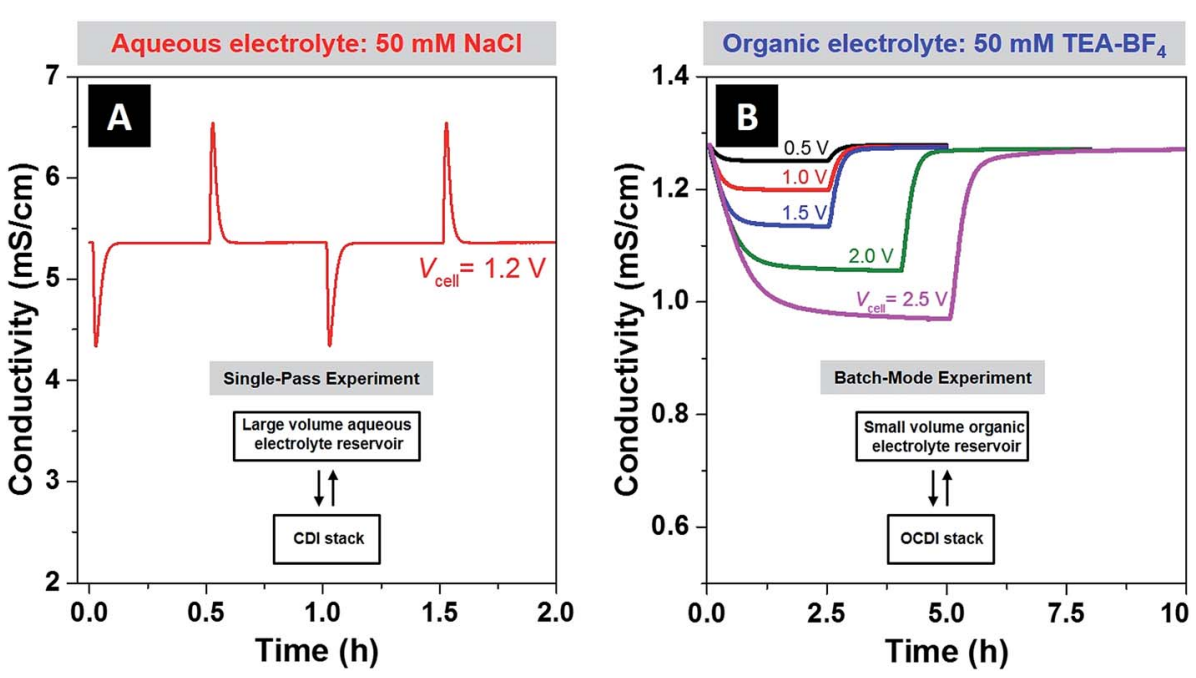

Fig. 2 Experimental data for effluent conductivity as function of time for (A) aqueous electrolyte with $\mathrm{NaCl}$ salt measured in single-pass mode utilizing water reservoir of $10.5 \mathrm{~L}$ inside which salt concentration remains very close to initial value during operation and (B) organic electrolyte with $\mathrm{TEA}-\mathrm{BF}_{4}$ salt measured in batch mode utilizing relatively small electrolyte reservoir inside which salt concentration changes during operation. Applied cell voltage, $V_{\text {cell }}$, equal to $1.2 \mathrm{~V}$, and initial salt concentration, $c_{\text {salt, }}$ equal to $50 \mathrm{mM}$.

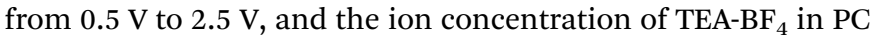
was $50 \mathrm{mM}$. At $2.5 \mathrm{~V}$, low leakage current of $0.3 \mathrm{~mA}$ (which was about $2 \%$ of the initial current) demonstrates the near absence of parasitic side-reactions at voltages well outside the water stability window in our CDI system. The reduction in feed conductivity at equilibrium was roughly $2 \%$ for $0.5 \mathrm{~V}, 11 \%$ for $1.5 \mathrm{~V}$, and $24 \%$ for $2.5 \mathrm{~V}$, demonstrating a large increase in achieved ion sorption when accessing higher voltages.

In Fig. 3, we show several commonly reported CDI performance metrics, ${ }^{2}$ and use these metrics to contrast the performance of the $\mathrm{NaCl} / \mathrm{H}_{2} \mathrm{O}$ and $\mathrm{TEA}-\mathrm{BF}_{4} / \mathrm{PC}$ systems. In Fig. $3 \mathrm{~A}$ we present the charge storage capacity as function of applied cell voltage. We find that at $1 \mathrm{~V}$, the charge stored is approximately $15 \mathrm{C} \mathrm{g}^{-1}$ for both systems tested. For TEA-BF 4 /PC system, due to wider electrochemical stability window, ${ }^{15}$ the measured charge storage capacity attains higher values than that of the aqueous system, up to about $49 \mathrm{C} \mathrm{g}^{-1}$ at $2.5 \mathrm{~V}$. Further, as shown in Fig. 3A, we observed a nonlinear increase of the charge stored (an increase in cell specific capacitance) with cell voltage, with specific capacitance increasing from about $44 \mathrm{~F} \mathrm{~g}^{-1}$ for voltages which were under $1.5 \mathrm{~V}$ to $78 \mathrm{~F} \mathrm{~g}^{-1}$ at $V_{\text {cell }}=2.5 \mathrm{~V}$ for the TEA$\mathrm{BF}_{4} / \mathrm{PC}$ system.

In Fig. 3B, we show the equilibrium salt adsorption capacity (eq-SAC) versus applied cell voltage for the case of $50 \mathrm{mM}$ ion concentration. The metric eq-SAC is widely used in the field of CDI to quantify the electrosorption performance of CDI electrodes, and is typically measured experimentally through $\mathrm{NaCl}$ electrosorption. $^{2}$ The maximum eq-SAC achieved by state-of-theart capacitive CDI electrodes is roughly $15 \mathrm{mg} \mathrm{g}^{-1}$ for the $\mathrm{NaCl} /$ $\mathrm{H}_{2} \mathrm{O}$ electrolyte. ${ }^{2}$ Since we want to compare $\mathrm{NaCl} / \mathrm{H}_{2} \mathrm{O}$ and TEA$\mathrm{BF}_{4} / \mathrm{PC}$ systems, using eq-SAC with units $\mathrm{mg} \mathrm{g}^{-1}$ is not an adequate metric due to the significantly higher molar mass of TEA-BF 4 compared to $\mathrm{NaCl}$ (roughly four times higher). Rather, a better metric which eliminates the effect of ion mass is eq-SAC using units of $\mathrm{mmol} \mathrm{g}^{-1}$. As can be seen in Fig. 3B, the $\mathrm{NaCl} / \mathrm{H}_{2} \mathrm{O}$ system achieves about $0.135 \mathrm{mmol} \mathrm{g}^{-1}$ at $1.2 \mathrm{~V}$, whereas the TEA$\mathrm{BF}_{4} / \mathrm{PC}$ system achieves over $0.35 \mathrm{mmol} \mathrm{g}^{-1}$ at $2.5 \mathrm{~V}$. Further, the eq-SAC in $\mathrm{mmol} \mathrm{g}^{-1}$ of both systems roughly overlaps at voltages between 0 and $1.2 \mathrm{~V}$, whereas the eq-SAC of the TEA-BF ${ }_{4}$ system continues to increase after $1.2 \mathrm{~V}$ due to the extended voltage window. Thus, we here observe that it is possible to achieve nearly three times higher salt sorption when using electrolyte with extended electrochemical stability window. In ESI Fig. S4, $\dagger$ we provide a comparison between TEA-BF $4 / \mathrm{PC}$ and $\mathrm{NaCl} / \mathrm{H}_{2} \mathrm{O}$ in terms of eq-SAC with units of $\mathrm{mg} \mathrm{g}^{-1}$, showing that the TEA-BF 4 PC system can achieve up to $76 \mathrm{mg}^{-1}$.

In Fig. 3C we plot the charge efficiency $(\Lambda)$ versus applied cell voltage for both systems (see also ESI Fig. S5A $\dagger$ ). The charge efficiency $\Lambda$ is defined as the ratio of charge (ions) removed from the feed stream to electrode surface charge at the end of the charge step, where measured $\Lambda$ is less than unity due to the effect of co-ion expulsion from the carbon nanopores. ${ }^{\mathbf{1 6}, 17}$ This metric is of high importance in CDI as the electrical energy consumption per ion removed scales as $1 / \Lambda .^{4}$ As can be seen in Fig. 3C, for $\mathrm{NaCl} / \mathrm{H}_{2} \mathrm{O}$ and $\mathrm{TEA}-\mathrm{BF}_{4} / \mathrm{PC}$, the measured $\Lambda$ generally increases with cell voltage and decreasing ionic strength.

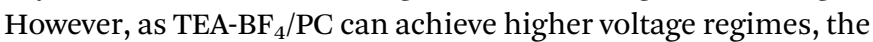
attained $\Lambda$ (and so attained energy efficiency) is also slightly higher, with $\Lambda \approx 92 \%$ at $5 \mathrm{mM}$ and $2.5 \mathrm{~V}$ for CDI with organic solvent (compared to $\sim 85 \%$ for CDI at $1.1 \mathrm{~V}$ and $5 \mathrm{mM}$ ).

In Fig. 3D, we show the equilibrium concentration of counterions and co-ions in the carbon nanopores derived from experimental data, as functions of electric charge normalized by the nanopore volume. The data is shown for both $\mathrm{NaCl} / \mathrm{H}_{2} \mathrm{O}$ and

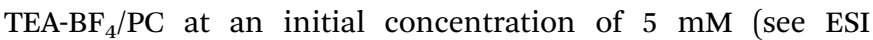
Fig. $\mathrm{S} 5 \mathrm{~B} \dagger$ for $50 \mathrm{mM}$ data). We further compare the experimentally derived data with the results of an improved modified Donnan (i-mD) model, which captured the data well (see ESI $\dagger$ and ref. 18 for details on the i-mD model). The data was obtained using the i-mD model to calculate initial micropore 

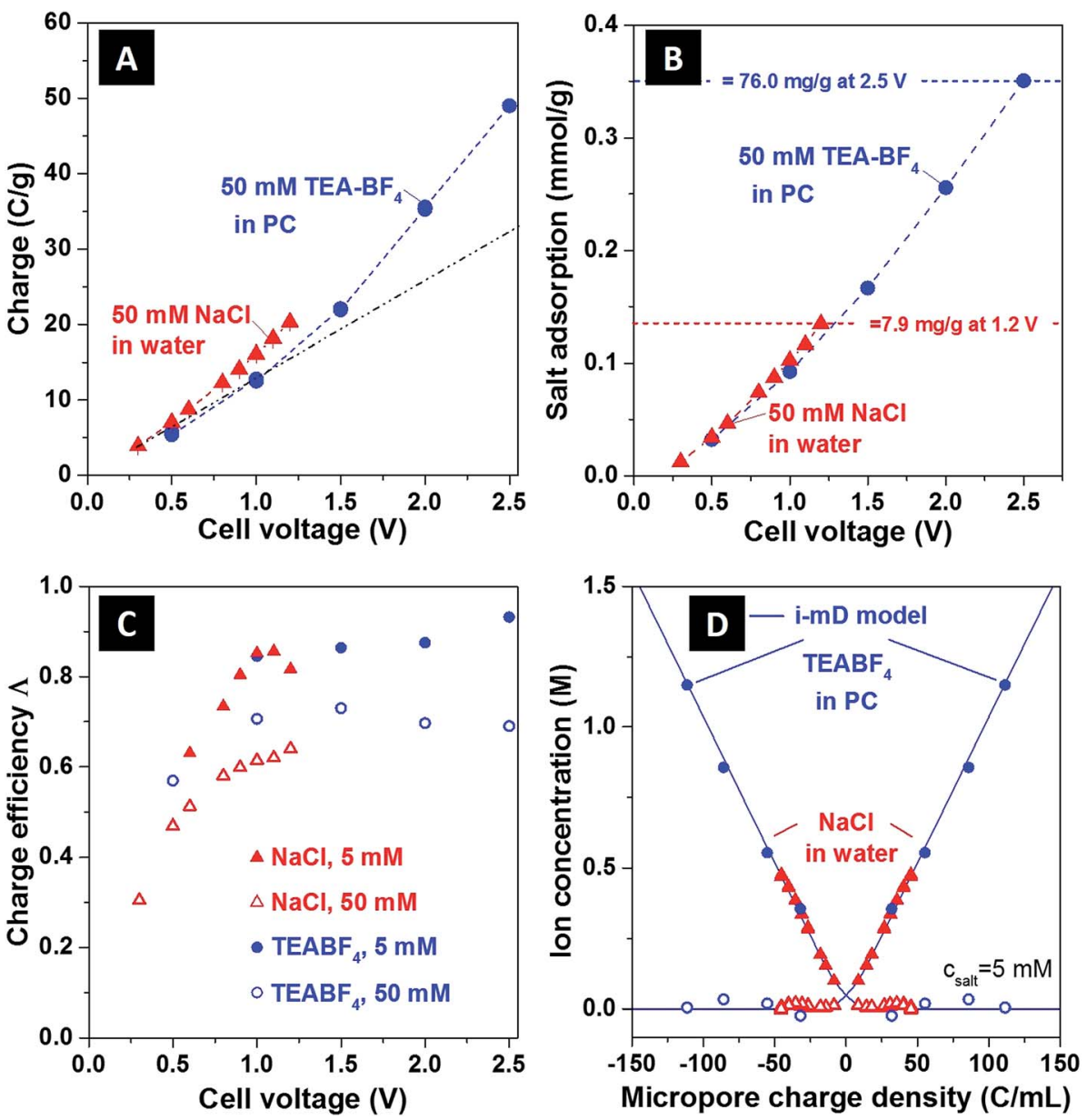

Fig. 3 Comparison between (A) charge storage, (B) salt adsorption, (C) charge efficiency as function of cell voltage, and (D) ion concentration as function of ionic charge density of aqueous and organic CDI systems, (assuming $E=200 \mathrm{kT} \mathrm{mM}^{-1}, 12 v_{\text {pore }}=0.736 \mathrm{~mL} \mathrm{~g}$ ). In panel (B), salt

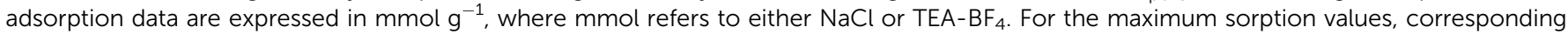
values in $\mathrm{mg} \mathrm{g}^{-1}$ are given; also, see ESI Fig. S4 $\uparrow$ for a full representation in $\mathrm{mg} \mathrm{g}^{-1}$. The black dashed line in (A) is a line of best fit through the organic system data points less than $1.5 \mathrm{~V}$ (blue circles), extrapolated to $2.5 \mathrm{~V}$, in order to show clearly the non-linear increase in measured charge stored at $>1.5 \mathrm{~V}$. The blue dashed lines in $\mathrm{A}$ and $\mathrm{B}$ follow the data points for the organic system in order to guide the eye, and the solid blue line in (D) are the $\mathrm{i}-\mathrm{mD}$ model results.

concentration, ${ }^{\mathbf{1 2}}$ and the measured ion removal from solution at equilibrium from effluent conductivity measurements (see ESI $\dagger$ for more details). For the aqueous system at $V_{\text {cell }}=1.2 \mathrm{~V}$, we calculate from measured data that the counterion concentration is $\sim 0.47 \mathrm{M}$, while for organic system at a cell voltage of $V_{\text {cell }}=2.5 \mathrm{~V}$ this value can be as high as $1.15 \mathrm{M}$, more than 23-times higher than initial concentration in the initially uncharged electrodes.

To advance the field of electrosorption technologies, significant research has been recently conducted in the field of in situ electrochemical characterization of supercapacitors. Advanced tools, such as nuclear magnetic resonance (NMR) spectroscopy, ${ }^{19,20}$ electrochemical quartz crystal microbalance (eQCM), ${ }^{21-23}$ electrochemical in situ small-angle X-ray scattering, ${ }^{24}$ in situ infrared spectroelectrochemistry, ${ }^{25}$ in situ ion concentration neutron imaging, and combination of such techniques, ${ }^{26}$ have been successfully employed to probe the ion concentration and redistribution dynamics in carbon nanopores undergoing electric charge compensation (during charging). One important result demonstrated by these studies is that at high concentrations $(\geq 1$ $\mathrm{M})$, during cell charging and discharging, ion populations inside porous carbon particles typically do not significantly change because charge compensation is mostly accomplished by ion swapping (i.e., exchanging one cation with one anion to accommodate two negative electric charges). ${ }^{27,28}$ These findings are relevant for high ionic concentrations; yet, at lower salt concentrations $(<100 \mathrm{mM})$, another mechanism needs to be considered: preferred counterion adsorption. ${ }^{29}$ The latter can occur when the initial concentration of ions in carbon nanopores is too low to accommodate the increased electric charge via ion swapping, and this mechanism can be leveraged towards energy-efficient ion removal (as in CDI). We note that the transition between these charge-compensation electrosorption mechanisms may not only vary as a function of state-of-charge and initial ion concentration, but also is sensitive to the type of salt and solvent system, and the co-ion and counterion kinetics. ${ }^{23,30}$

The measurement technique demonstrated here to capture the equilibrium ion concentration in carbon nanopores can give 
insights into the ion compensation mechanisms without the use of highly complex NMR or eQCM measurements. For example, the data in Fig. 3D shows quantitatively that the mechanism of counterion adsorption dominates and co-ion expulsion also occurs to a more limited extent. As the charge (cell voltage) is increased, the counterion concentration in the pore is greatly increased while the co-ion is reduced to near-zero concentration. Effectively, we see that counterion adsorption only dominates when the reservoir of co-ions becomes depleted. Thus, taken as a whole, the technique coupling the i-mD model and effluent conductivity measurements allows us to link key parameters of the porous carbons, such as charge storage, nonelectrostatic attraction energy, and pore volume, to the ion distribution in the nanopores. We note that the $\mathrm{i}-\mathrm{mD}$ model neglected the effects of steric ion exclusion on electrode capacitance. This effect has, to our knowledge, never been incorporated into CDI theory as CDI typically uses small ions, such as sodium and chloride, which are assumed to be able to enter unobstructed into the entire distribution of carbon nanopores. Here, for organic electrolyte, we use larger $\mathrm{TEA}^{+}$ ions, which can be sterically excluded from pores below around $0.7 \mathrm{~nm} .{ }^{31}$ We expect that the latter effect will result in asymmetric systems, with differing nanopore volumes available to the larger $\mathrm{TEA}^{+}$and smaller $\mathrm{BF}_{4}{ }^{-}$ions during cell charging (see ESI Table S1 and Fig. S1†).

Further insights can be gained on the local environment in carbon nanopores when considering the ratio of ion volume to available pore volume (the micropore volume of the carbon particles used in our electrodes). This ratio is shown in ESI Fig. S6, $\uparrow$ and the obtained results suggest that ion desolvation during charging has to be considered for CDI system with TEA$\mathrm{BF}_{4}$ in PC (at least for the ionic system used in our study). The presence of significant ion desolvation has previously been inferred in porous carbon systems from works studying the influence of average pore size on the charge storage ability of supercapacitors, ${ }^{31,32}$ and has been demonstrated via molecular dynamics model results. ${ }^{33,34}$

In conclusion, our study demonstrates the potential of CDI technology for the application of ion-based separations in electrolytes using organic solvents. Our work demonstrated a first time extension of the CDI voltage window to $2.5 \mathrm{~V}$ due to the use of organic solvents with $>2 \mathrm{~V}$ decomposition potentials. We also provided an experimental study of ion removal at voltages beyond the water electrolysis window, showing higher salt adsorption is possible in CDI applied to aqueous electrolytes. Finally, we demonstrated a simple and insightful method to link commonly reported properties of carbon electrodes, such as salt adsorption capacity, with ion concentrations inside nanopores as a function of applied cell voltage. While our proofof-concept system uses the salt/solvent system of tetraethylammonium tetrafluoroborate salt $\left(\mathrm{TEA}^{\left.-\mathrm{BF}_{4}\right)}\right.$ dissolved in propylene carbonate (PC), the same concept can be performed with a wide variety of organic solvents, charged molecules, and applications (such as lithium recovery or recycling or organic solvents used for purification of synthesis product and cleaning of equipment in the chemical industry). ${ }^{35,36}$ Especially the possibility to employ CDI for reducing the amount of needed organic solvent in the pharmaceutical industry is of great interest, considering that solvents account for $80-90$ mass $\%$ of the total utilized materials. ${ }^{37}$

\section{Acknowledgements}

S. P. acknowledges financial support of the Alexander von Humboldt Foundation (AVH). V. P. acknowledges financial support by the German Research Foundation via the Heinz Maier-Leibnitz Prize. S. P. and V. P. thank Prof. Eduard Arzt (INM) for his continuing support. The authors thank Dr Maarten Biesheuvel (Wetsus) and Dr Daniel Weingarth (INM) for their support and value discussion. The authors also thank Marco Zeiger (INM) for his help with Raman spectroscopy and electron microscopy, and Nicolas Jäckel (INM) for his support with gas sorption analysis.

\section{References}

1 H. Wang, T. K. J. Köster, N. M. Trease, J. Ségalini, P.-L. Taberna, P. Simon, Y. Gogotsi and C. P. Grey, J. Am. Chem. Soc., 2011, 133, 19270-19273.

2 M. E. Suss, S. Porada, X. Sun, P. M. Biesheuvel, J. Yoon and V. Presser, Energy Environ. Sci., 2015, 8, 2296-2319.

3 P. M. Biesheuvel and M. Z. Bazant, Phys. Rev. E: Stat., Nonlinear, Soft Matter Phys., 2010, 81, 031502.

4 S. Porada, R. Zhao, A. van der Wal, V. Presser and P. M. Biesheuvel, Prog. Mater. Sci., 2013, 58, 1388-1442.

5 R. Zhao, M. van Soestbergen, H. H. M. Rijnaarts, A. van der Wal, M. Z. Bazant and P. M. Biesheuvel, J. Colloid Interface Sci., 2012, 384, 38-44.

6 S. H. Roelofs, B. Kim, J. C. Eijkel, J. Han, A. van den Berg and M. Odijk, Lab Chip, 2015, 15, 1458-1464.

7 R. Zhao, S. Porada, P. M. Biesheuvel and A. van der Wal, Desalination, 2013, 330, 35-41.

8 H.-H. Jung, S.-W. Hwang, S.-H. Hyun, K.-H. Lee and G.-T. Kim, Desalination, 2007, 216, 377-385.

9 X. Xu, L. Pan, Y. Liu, T. Lu, Z. Sun and D. H. C. Chua, Sci. Rep., 2015, 5, 8458.

10 X. Xu, Z. Sun, D. H. C. Chua and L. Pan, Sci. Rep., 2015, 5, 11225.

11 P. M. Biesheuvel, M. E. Suss and H. V. M. Hamelers, 2015, Arxiv, 1506.03948.

12 T. Kim, J. E. Dykstra, S. Porada, A. van der Wal, J. Yoon and P. M. Biesheuvel, J. Colloid Interface Sci., 2015, 446, 317-326.

13 P. Marchetti, M. F. Jimenez Solomon, G. Szekely and A. G. Livingston, Chem. Rev., 2014, 114, 10735-10806.

14 D. Weingarth, M. Zeiger, N. Jäckel, M. Aslan, G. Feng and V. Presser, Adv. Energy Mater., 2014, 4, 1400316.

15 F. Markoulidis, C. Lei, C. Lekakou, D. Duff, S. Khalil, B. Martorana and I. Cannavaro, Carbon, 2014, 68, 58-66.

16 P. M. Biesheuvel, R. Zhao, S. Porada and A. van der Wal, J. Colloid Interface Sci., 2011, 360, 239-248.

17 J.-B. Lee, K.-K. Park, H.-M. Eum and C.-W. Lee, Desalination, 2006, 196, 125-134.

18 P. M. Biesheuvel, S. Porada, M. Levi and M. Z. Bazant, J. Solid State Electrochem., 2014, 18, 1365-1376. 
19 H. Wang, A. C. Forse, J. M. Griffin, N. M. Trease, L. Trognko, P.-L. Taberna, P. Simon and C. P. Grey, J. Am. Chem. Soc., 2013, 135, 18968-18980.

20 Z. X. Luo, Y. Z. Xing, Y. C. Ling, A. Kleinhammes and Y. Wu, Nat. Commun., 2015, 6, 6358.

21 M. D. Levi, G. Salitra, N. Levy, D. Aurbach and J. Maier, Nat. Mater., 2009, 8, 872-875.

22 M. D. Levi, N. Levy, S. Sigalov, G. Salitra, D. Aurbach and J. Maier, J. Am. Chem. Soc., 2010, 132, 13220-13222.

23 W.-Y. Tsai, P.-L. Taberna and P. Simon, J. Am. Chem. Soc., 2014, 136, 8722-8728.

24 C. Prehal, D. Weingarth, E. Perre, R. T. Lechner, H. Amenitsch, O. Paris and V. Presser, Energy Environ. Sci., 2015, 8, 1725-1735.

25 F. W. Richey, B. Dyatkin, Y. Gogotsi and Y. A. Elabd, J. Am. Chem. Soc., 2013, 135, 12818-12826.

26 J. M. Griffin, A. C. Forse, W. Y. Tsai, P. L. Taberna, P. Simon and C. P. Grey, Nat. Mater., 2015, 14, 812-819.

27 M. Deschamps, E. Gilbert, P. Azais, E. Raymundo-Piñero, M. R. Ammar, P. Simon, D. Massiot and F. Béguin, Nat. Mater., 2013, 12, 351-358.
28 S. Kondrat, P. Wu, R. Qiao and A. A. Kornyshev, Nat. Mater., 2014, 13, 387-393.

29 J. M. Griffin, A. C. Forse, H. Wang, N. M. Trease, P. L. Taberna, P. Simon and C. P. Grey, Faraday Discuss., 2015, 176, 49-68.

30 C. Péan, C. Merlet, B. Rotenberg, P. A. Madden, P.-L. Taberna, B. Daffos, M. Salanne and P. Simon, ACS Nano, 2014, 8, 1576-1583.

31 J. Chmiola, C. Largeot, P.-L. Taberna, P. Simon and Y. Gogotsi, Angew. Chem. Int. Ed., 2008, 47, 3392-3395.

32 J. Chmiola, G. Yushin, Y. Gogotsi, C. Portet, P. Simon and P. L. Taberna, Science, 2006, 313, 1760-1763.

33 D. Jiang, Z. Jin, D. Henderson and J. Wu, J. Phys. Chem. Lett., 2012, 3, 1727-1731.

34 D. Jiang, Z. Jin and J. Wu, Nano Lett., 2011, 11, 5373-5377. 35 Y. Liu, L. Pan, X. Xu, T. Lu and Z. Sun, RSC Adv., 2013, 3, 16932-16935.

36 T. Ryu, D.-H. Lee, J. C. Ryu, J. Shin, K.-S. Chung and Y. H. Kim, Hydrometallurgy, 2015, 151, 78-83.

37 D. J. C. Constable, C. Jimenez-Gonzalez and R. K. Henderson, Org. Process Res. Dev., 2007, 11, 133-137. 